\title{
The Random Vibration Analysis for the Frame of Traction Lift Transport Platform Based on Ansys
}

\author{
Min Yuan ${ }^{1, a}$, Kun Wang ${ }^{1, b}$, Bin $X u^{2, c}$, Qing Feng ${ }^{1, d}$, Aiman $W u^{1, e}$ \\ ${ }^{1}$ The Engineering \& Technical College of Chengdu University of Technology, Leshan, 614004 ,China \\ ${ }^{2}$ Leshan Vocational and Technical College, Leshan, 614099, China \\ a421436821@qq.com, b541756437@qq.com, ' $185470792 @ q q . c o m,{ }^{d} 649576480 @ q q . c o m,{ }^{e} 2918$
} 07248@qq.com

Keywords: Random Vibration, Frame, Ansys

\begin{abstract}
Firstly, a brief introduction of the relevant theory of spectral density is made. Then the stochastic road irregularities are established based on the above theory. Finally, the random vibration analysis is made based on the results of pre-stressed modal analysis in Ansys/workbench.
\end{abstract}

\section{Background and Significance of the Study}

The traction lift transport platform (hereinafter “transport platform”) is specially designed for loading, unloading and transshipment of large equipment and large instrument .In this way, the abrasion of related equipment can be effectively reduced in the long distance transport process. And the life of the equipment can be improved accordingly. Also, the transport platform can be used as a stable working platform for certain instruments or equipment (such as optical tracking equipment and radar). Instruments or equipment can finish the job on the transport platform. The frame is one of the important structures of the transport platform, and the proportion of the mass is the highest. The platform components are installed on the frame. As the part of load carrying, the performance of the system is affected by the frame.

The pavement roughness is uncertain in the process of transporting. The pavement random excitation is made to the transport platform accordingly [1]. Then the vertical (the $\mathrm{X}$ direction) random displacement is shown on the transport platform. If the above random excitation is too strong, the fatigue damage of the structure will be caused. The transport platform must have a high level of reliability, which is determined by the nature of the transport platform. Therefore, the random vibration analysis for the frame is of great significance.

\section{Introduction to the Theory}

As a kind of qualitative analysis, random vibration analysis can also be called power spectral density analysis (PSD) [1].By the random vibration analysis, the values of physical parameters (such as the probability distribution of displacement or stress )will be solved under the action of random excitation to the structure. Nowadays the random vibration analysis of has been widely used on the design for airborne electronic equipment, acoustic loading components and optical alignment equipment.

Power spectral density is the probability statistics for the response of the structure under random dynamic load. The displacement power spectral density, the speed power spectral density, the acceleration power spectral density, the strength power spectral density is included in the power spectral density. In mathematics, the value of the area bounded by the power spectral density value frequency curve is equal to the variance [3]. Mode shape and natural frequency of each order is be solved by the modal analysis. Then the finite element random vibration analysis can calculate the response of structure under random excitation according to the displacement spectrum.

\section{Random Vibration Analysis}


Spectrum Value Calculation. The displacement time frequency power spectrum density $G_{q}(f)$ of the pavement is as the input in the random vibration analysis. The response results are inconsistent for different pavement level and different speed. According to value of pavement roughness coefficient $G_{q}\left(n_{0}\right)$, the road is generally divided into 8 levels in the standard [1]. The value of pavement spectrums is usually distributed in the range of level A, level B and level C. Among them, the proportion of level B and level $\mathrm{C}$ is bigger than the other. The speed of the transport platform is around $40 \mathrm{~km} / \mathrm{h}$. The value of displacement time frequency power spectral density under the speed of $40 \mathrm{~km} / \mathrm{h}$ at the $\mathrm{C}$ level pavement can be calculated according to Tab.1. The excitation is exerted on the frame along the $\mathrm{X}$-axis in the form of base excitation.

Tab.1 The pavement power spectral density value

\begin{tabular}{ccc}
\hline serial & & $\mathrm{V}=40 \mathrm{~km} / \mathrm{h}, \mathrm{C}$ level \\
\cline { 3 - 3 } number & frequency & the value of spectrum $\left(\times 10^{-6} \mathrm{~m}^{2} / \mathrm{Hz}\right)$ \\
\hline 1 & 23.64 & $1.83234 \mathrm{E}-07$ \\
2 & 31.208 & $1.0514 \mathrm{E}-07$ \\
3 & 36.056 & $7.87671 \mathrm{E}-08$ \\
4 & 42.697 & $5.61701 \mathrm{E}-08$ \\
5 & 54.592 & $3.43591 \mathrm{E}-08$ \\
6 & 58.42 & $3.00038 \mathrm{E}-08$ \\
7 & 62.176 & $2.64883 \mathrm{E}-08$ \\
8 & 71.677 & $1.99315 \mathrm{E}-08$ \\
9 & 89.357 & $1.28246 \mathrm{E}-08$ \\
10 & 90.078 & $1.26201 \mathrm{E}-08$ \\
\hline
\end{tabular}

The Results of the Analysis. The finite model is established in Ansys/workbench, and the loads are exerted according to the table 1 . The speed, acceleration and the corresponding equivalent stress with six degrees of freedom of the nodes can be calculated through the random vibration analysis. According to the theory of probability and statistics, the value of response value refers to the value of root mean square under the normal distribution. The probability is $68.27 \%$ in the condition that response value is less than the root mean square value.

Excitation is exerted on the frame along the $\mathrm{X}$ axis. As a result the equivalent stress distribution, the displacement along the $\mathrm{X}$ axis, velocity along the $\mathrm{X}$ axis and acceleration distribution along the $\mathrm{X}$ axis can be obtained by analysis. Equivalent stress distribution of frame is shown in Fig. 1. Meanwhile the figure presents the uniformity of the equivalent stress distribution of the whole frame. Therefore the design can be considered to be reasonable. The maximum value of stress is $98.8 \mathrm{Mpa}$, which is located at projection of the rear of the frame.

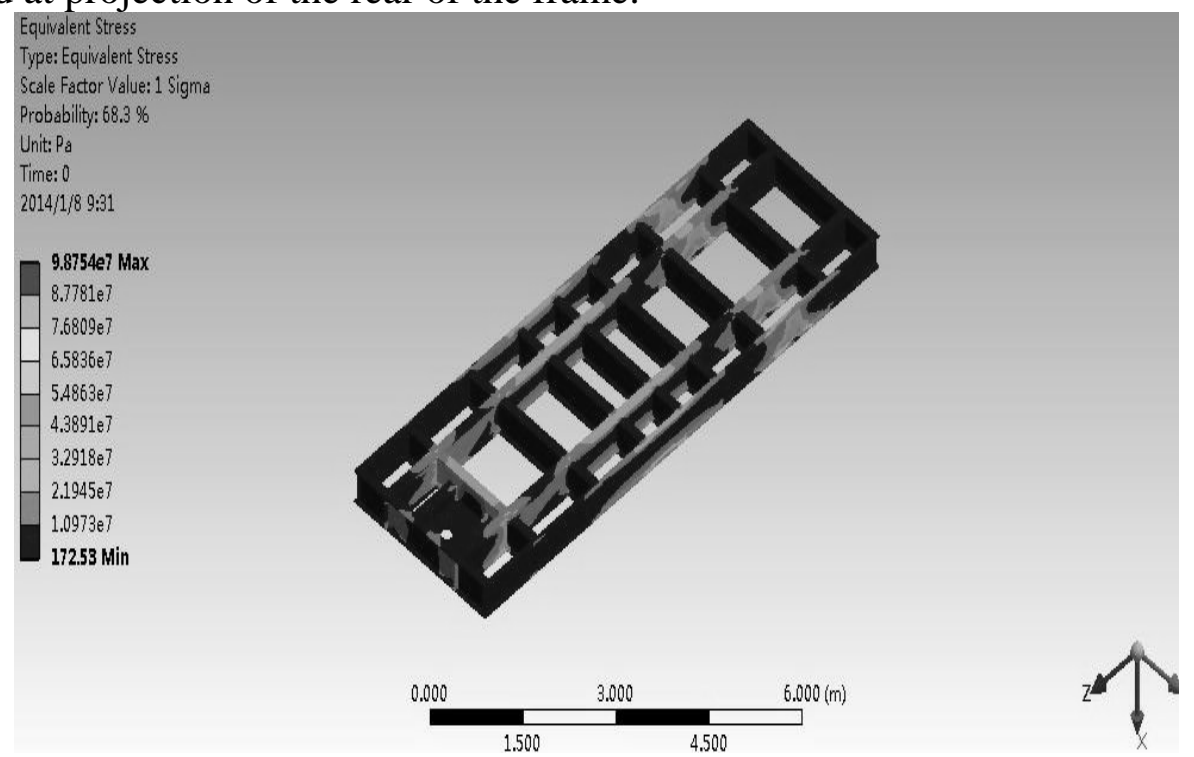

Fig.1 Equivalent stress contours 
The deformation in $\mathrm{X}$ direction is shown in Fig.2.The largest value of displacement of the frame deformation is $1.85 \mathrm{~mm}$, which is located in the area without support in the front of the frame.

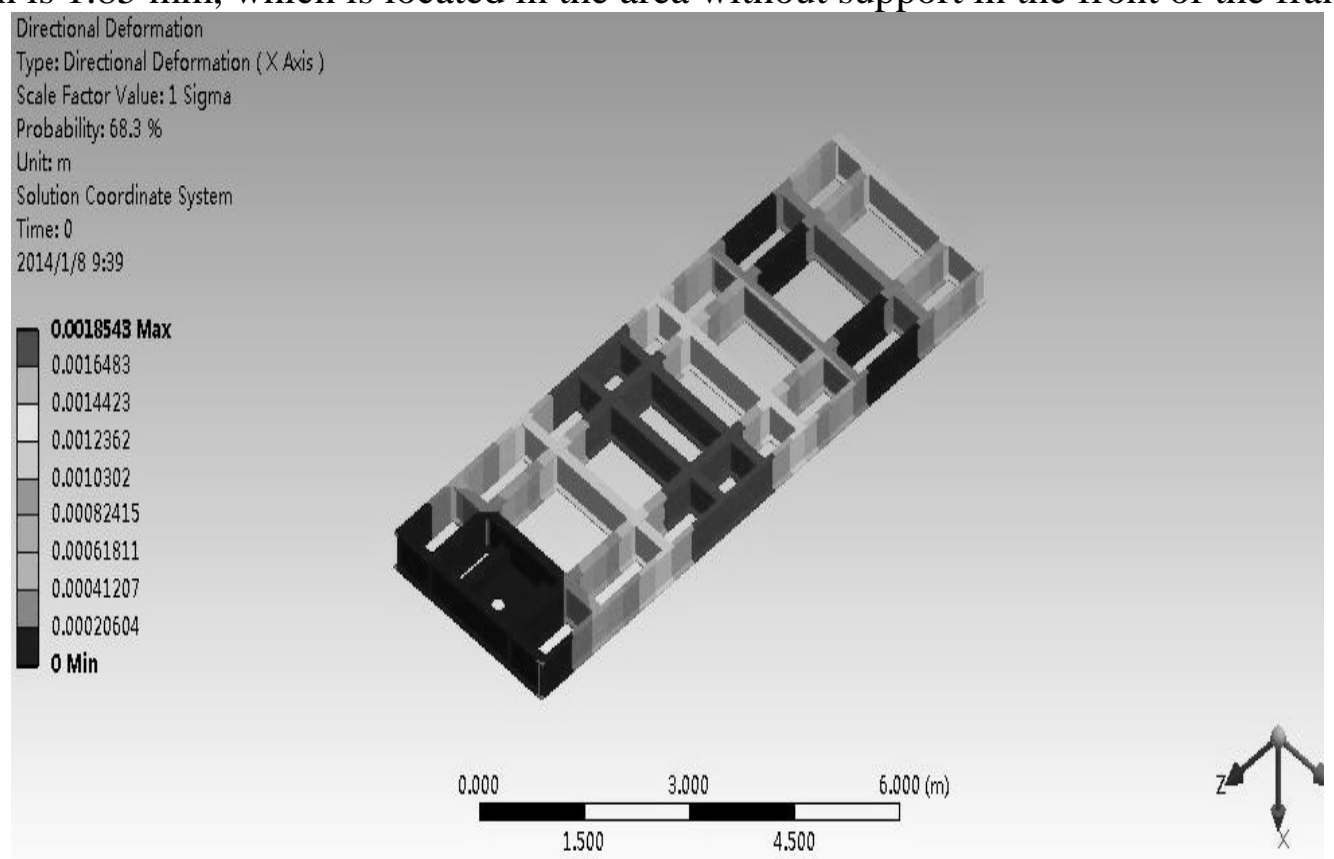

Fig.2 The deformation in $\mathrm{X}$ direction

The Post-processing is conducted by combining Ansys/workbench and classic interface. The values of $\mathrm{X}$ direction displacement deformation are sorted in descending order. Then the Serial number of node with maximum value is 52416 .

The displacement, velocity and acceleration response spectrum curve of the node with largest value of deformation is respectively shown in Fig.3, Fig.4 and Fig.5.

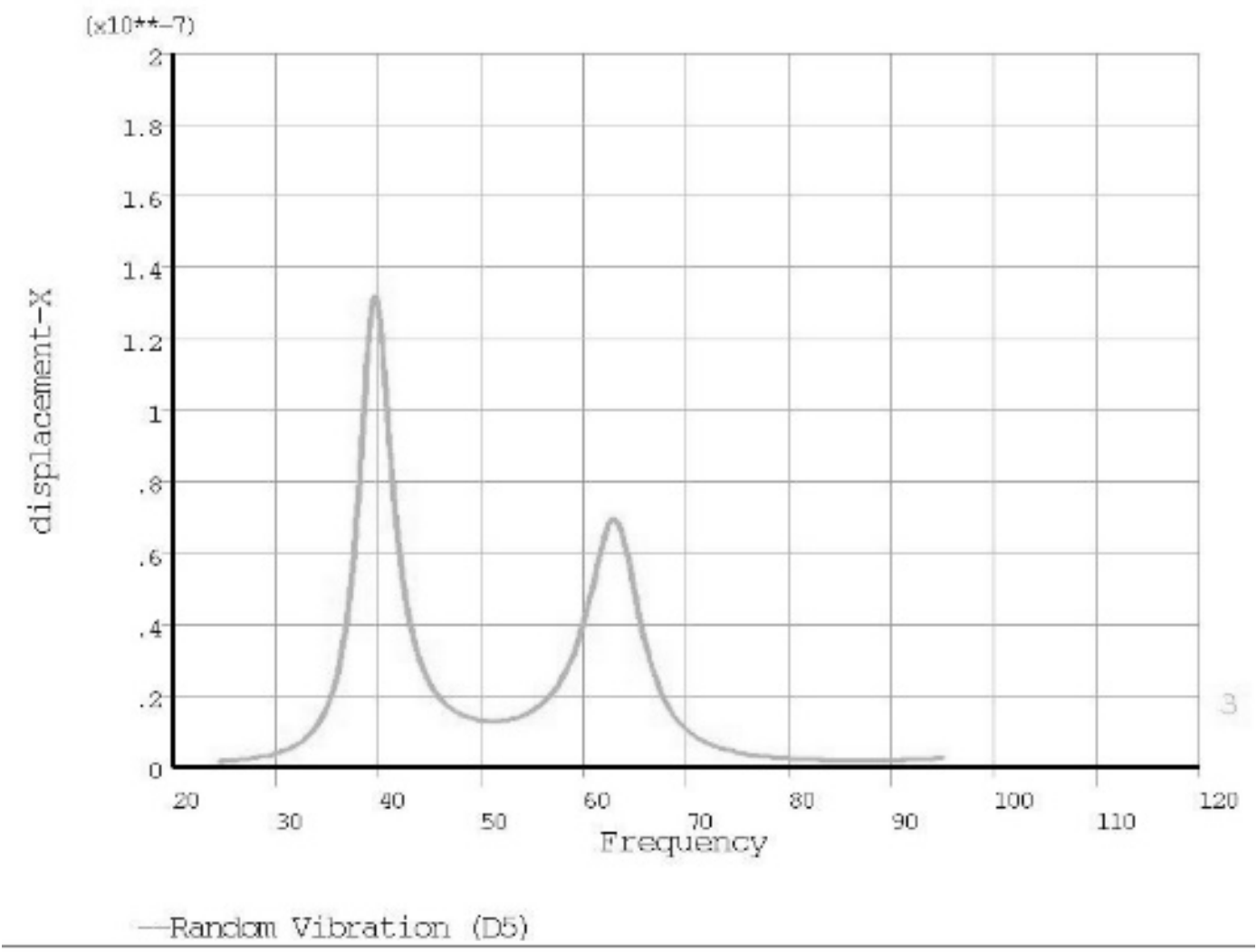

Fig.3 Equivalent stress contours 


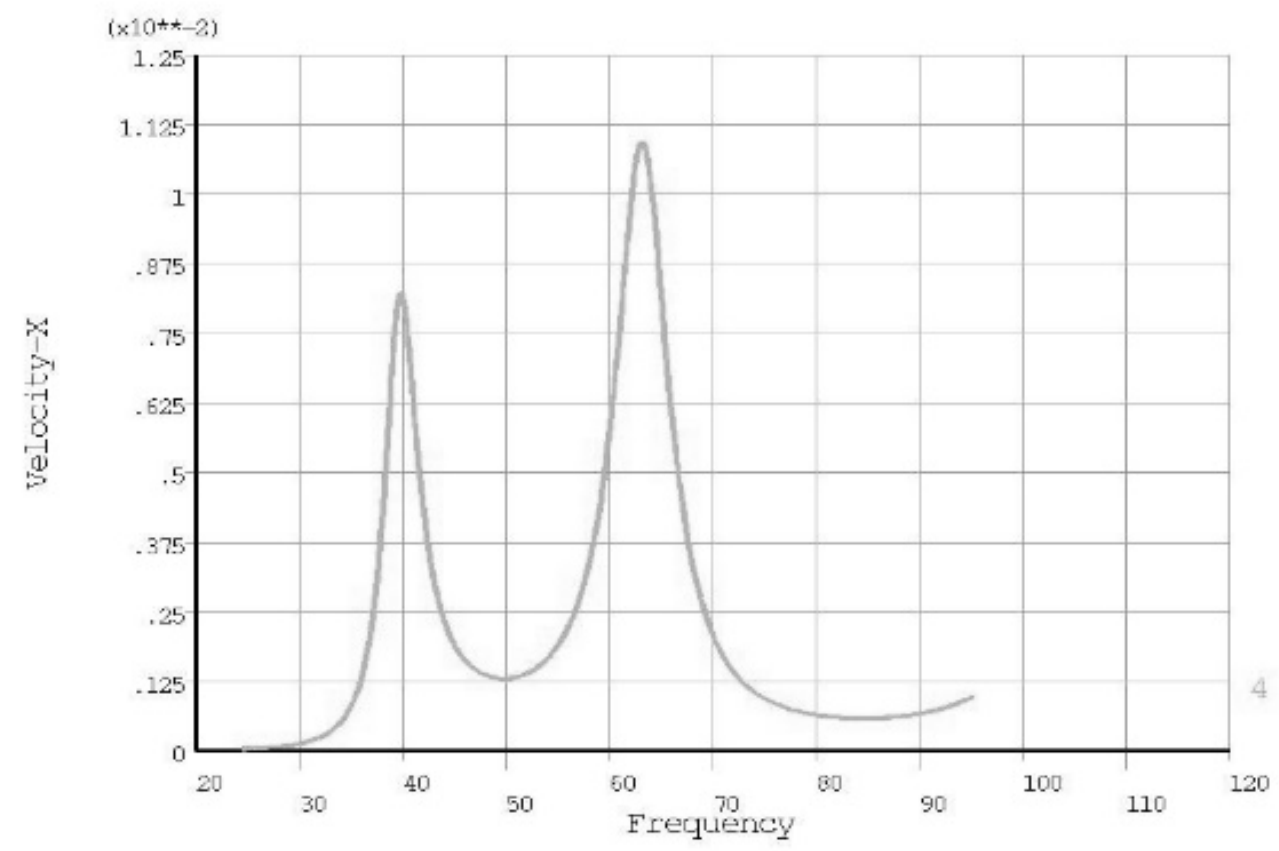

--Randam Vibration (D5)

Fig.4 The deformation in $\mathrm{X}$ direction

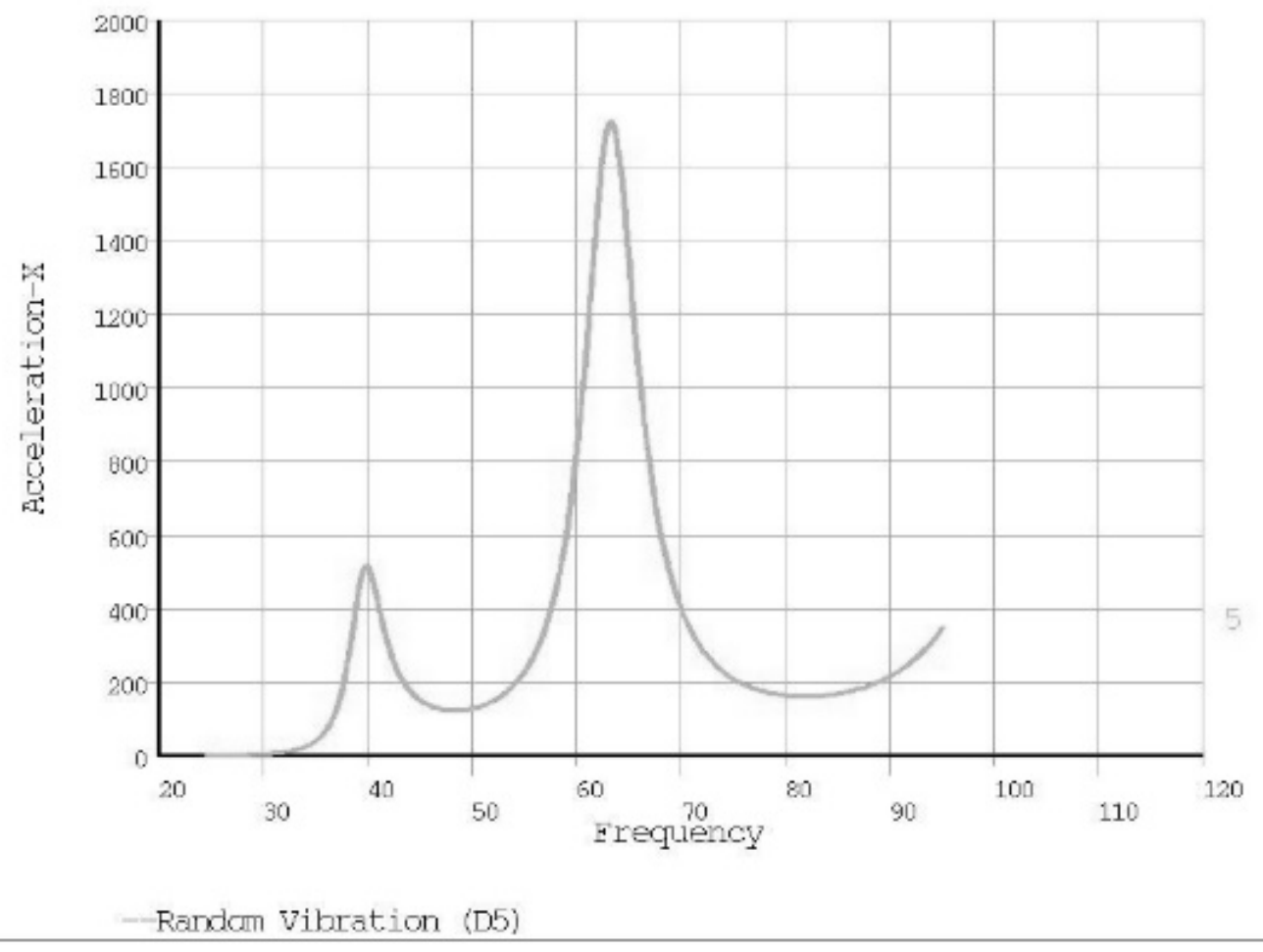

Fig. 5 The deformation in $\mathrm{X}$ direction

The analysis shows that the peak of each figure is the same. An analysis of pavement displacement response spectrum curve of the node with largest value of deformation is made. When the value of frequency is $39.6 \mathrm{~Hz}$, the vibration displacement is the biggest. The frequency value is very similar to the value of the second pre-stressed modal. The frequency value of the other parts must be avoided with the above value in order to avoid resonance. The influence of the vibration to the structure is generally weighed with acceleration response. The Fig.5 shows that the value of the acceleration response at the frequency of $63.3 \mathrm{~Hz}$ is the biggest. The value of the above frequency is more than the value of pavement excitation frequency, so resonance will not be occurred. The response caused by the first five frequency is weak. So the influence on the instrument is low accordingly. 


\section{Conclusion}

The random vibration analysis for the transport platform is made by the finite software Ansys. By the analysis of finite element calculation, the results of the stress, displacement and acceleration random vibration are obtained. By evaluating the response of the frame structure under random pavement excitation, the rationality of the design of the structure can be estimated. And the analysis can provide a reference for optimizing structure design. Finally the frame can improve the performance of the whole transport platform.

\section{Acknowledgement}

This thesis is supported by the Scientific Research Foundation of the Education Department of Sichuan Province (17ZB0067) and Science Foundation for Youths of the Engineering\&Technical College of Chengdu University of Technology (C122016018).

\section{References}

[1] Wenhui Lv.finite element analysis optimizationdesign tanktransport semi-trailer frame structure [D].Shanghai:Shanghai Jiaoyong University,2006.

[2] Bendsoe M P, Kikuchi N.Generating optimal topologies in structural design using a homogenization method [J]. Computational methods in applied mechanics and engineering, 1988, 71 (2):197-244

[3] Martin P. Bendsoe, Ole Sigmund. Topology Optimization: Theory, Methods and Applications [M]. Springer Group, 2002.

[4]Hong Seok Lim,Yong Woo Kim,Man Hoi Koo,Hak In Gimm and Hong Hee Yoo. Two-stage design process of a frame-panel land vehicle structure employing topology and cross section optimization [J]. Journal of Mechanical Science and Technology, 2010, 24(10): 1963-1967.

[5] Emil Norberg Sebastian Lövgren. Topology Optimization of Vehicle Body Structure for improved Ride \& Handling [D].Linkoping: Linkopings universitet, 2011.

[6] Christensen, Peter W, Klarbring, Anders. An Introduction to Structural Optimization [M]. Springer Group, 2009. 